\title{
Use of the health care system by Ontario First Nations people with diabetes: a population-based study
}

\author{
Baiju R. Shah MD PhD, Morgan Slater PhD, Eliot Frymire MA, Kristen Jacklin PhD, \\ Roseanne Sutherland, Shahriar Khan MSc, Jennifer D. Walker PhD, Michael E. Green MD MPH
}

See related article at www.cmajopen.ca/lookup/doi/10.9778/cmajo.20190096

Abstract

Background: First Nations people in Ontario have an increased prevalence of diabetes compared to other people in the province. This study examined use of health care services by First Nations people with diabetes and other people with diabetes in Ontario.

Methods: Using linked health administrative databases, we identified all people in Ontario with diabetes as of Apr. 1, 2014. We identified First Nations people using the Indian Register. We looked at outcomes from Apr. 1, 2014, to Mar. 31, 2015. We determined the proportion of people with a regular family physician and their continuity of care with that physician. We also examined visits with specialists for diabetes care, hospital admissions for ambulatory-care-sensitive conditions, and emergency department visits for hypo- or hyperglycemia.

Results: There were 1380529 people diagnosed with diabetes in Ontario as of Apr. 1, 2014, of whom 22 952 (1.7\%) were First Nations people. First Nations people were less likely to have a regular family physician $(85.3 \%$ v. $97.7 \%)$ and had lower continuity of care with that physician (mean score for continuity of care $74.6 \mathrm{v}$. 77.7) than other people in Ontario. They were also less likely to see specialists. First Nations people were more likely to be admitted to hospital for ambulatory-care-sensitive conditions $(2.4 \%$ v. $1.2 \%)$ and to have an emergency department visit for hypo- or hyperglycemia ( $1.5 \%$ v. $0.8 \%)$. Disparities were particularly marked for those living in First Nations communities.

Interpretation: First Nations people with diabetes in Ontario had poorer access to and use of primary care than other people with diabetes in the province. These findings may help explain continued disparities in the rates of complications related to diabetes.

$\mathrm{H}$ ealth care systems with strong primary care deliver better outcomes at lower costs and with fewer disparities, ${ }^{1,2}$ particularly among people with chronic diseases such as diabetes. ${ }^{3}$ First Nations people in Ontario have an increased prevalence of diabetes compared to other people in the province ${ }^{4}$ and experience complications from diabetes at elevated rates. ${ }^{5}$

First Nations people face unique geographic and sociopolitical barriers to diabetes care. Colonialism is a major contributor to socioeconomic and environmental marginalization, geographic and transportation barriers, and the fragmentation of responsibility for health care services. ${ }^{6-8}$ Racism, discrimination, unconscious bias and structural violence in the health care system also create barriers that keep Indigenous people from accessing health care services. ${ }^{9-12}$ The aim of this study was to determine whether family physician, specialist and hospital use by First Nations people with diabetes in Ontario differs from that of other people with diabetes in the province.

\section{Methods}

\section{Design, data sources and study population}

We conducted a retrospective population-based cohort study in Ontario. The general approach to cohort creation and the characteristics of the study cohort are described in detail elsewhere. ${ }^{13}$ Data evaluated in this study were sourced from comprehensive linked health administrative data sets related to Ontario's single-payer publicly funded health care system housed at ICES. The data sets used are described in Appendix 1 of our previous publication. ${ }^{13}$

\section{Competing interests: None declared.}

This article has been peer reviewed.

Correspondence to: Baiju Shah, baiju.shah@ices.on.ca

CMAJ Open 2020. DOI:10.9778/cmajo.20200043 
In brief, for this study, we identified all people with diagnosed nongestational diabetes in Ontario as of Apr. 1, 2014. We identified those who were First Nations using the Indian Register, which includes information for all people registered as Status First Nations people under the Indian Act. All other Ontario residents were classified as "other people in Ontario." First Nations people were also categorized as living in or outside of First Nations communities ("Indian reserves") by means of postal codes and other geographic information. ${ }^{13}$ Baseline characteristics ascertained for each patient included age, sex, location of residence (defined with the Rurality Index for Ontario score for each person's home address, classified into urban, semiurban, rural and remote) ${ }^{14}$ and comorbidity (defined with the Johns Hopkins Adjusted Clinical Group System Aggregated Diagnosis Groups). ${ }^{15}$

\section{Outcome measures}

We ascertained use of health care services from physician service claims for fee-for-service reimbursement, and from hospital discharge abstracts and emergency department encounter abstracts compiled by the Canadian Institute for Health Information. We determined 6 outcomes that spanned primary, specialist and hospital care for diabetes. First, we determined the proportion of people with diabetes who had a regular family physician by examining their registrations to a family physician under a primary care enrolment model, where patients are rostered with a specific family physician or team. We considered people who were not formally rostered to have a regular family physician if they had received any core primary care services such as periodic health examinations or vaccinations over the preceding 2 years. ${ }^{16}$ Second, we determined a score for continuity of family physician care among people who had a regular family physician and who had had at least 3 family physician visits over the preceding 2 years by calculating the proportion of their total family physician visits that were with their regular family physician.

We next examined secondary care by evaluating use of specialists for diabetes care. We ascertained any ambulatory visits with an endocrinologist (third outcome) and any ambulatory visits with a general internist (fourth outcome) between Apr. 1, 2014, and Mar. 31, 2015.

The fifth outcome was hospital admission for an ambulatory-care-sensitive condition between Apr. 1, 2014, and Mar. 31, 2015. Ambulatory-care-sensitive conditions are chronic medical conditions (asthma, chronic obstructive pulmonary disease, congestive heart failure or diabetes) for which adequate and timely primary care ought to reduce the requirement for hospital admission for these conditions. ${ }^{17,18}$

The sixth outcome was an emergency department visit for hypo- or hyperglycemia between Apr. 1, 2014, and Mar. 31, 2015. These conditions are acute complications of diabetes, as they indicate profound metabolic abnormalities that a patient cannot self-manage and instead requires medical assistance. We restricted these visits to unplanned emergency department visits triaged with a score of "urgent" or higher, to exclude emergency department visits that were substitutes for primary care visits (e.g., prescription renewals or scheduled follow-up with a family physician working an emergency department shift). Both hospital admissions for ambulatorycare-sensitive conditions and emergency department visits for hypo- or hyperglycemia are potentially preventable events, and so both can be considered markers for poor access to primary care. The International Statistical Classification of Diseases and Related Health Problems, 10th Revision diagnosis codes used for both are presented in Appendix 1, Supplemental Table S1 (available at www.cmajopen.ca/content/8/2/E313/ suppl/DC1).

\section{Statistical analysis}

For continuity of care, we determined the mean score among eligible people; all other outcomes were dichotomous and we determined the proportion of people with the outcome. All analyses were adjusted for age and sex, and $95 \%$ confidence intervals (CIs) were calculated. We compared First Nations people living in First Nations communities and those living outside of First Nations communities with other people in Ontario. Because living in rural or remote areas can influence use of health care services, all analyses were further stratified by location of residence. Analyses were conducted with SAS Enterprise Guide version 7.1 (SAS Institute).

\section{Ethics approval}

The study received research ethics review from Queen's University and Laurentian University. The project was also approved by the Chiefs of Ontario Data Governance Committee.

\section{Results}

There were 1380529 people diagnosed with diabetes in Ontario as of Apr. 1, 2014, of whom 22952 (1.7\%) were First Nations people. Table 1 shows the baseline characteristics of these populations. On average, First Nations people with diabetes were younger than other people with diabetes in Ontario, with 7516 (32.7\%) less than age 50 years, compared to 242423 other people (17.9\%), and a higher proportion were female $(53.6 \%$ v. $48.0 \%)$. First Nations people were also more likely to reside in rural and remote areas.

Table 2 shows each outcome across the populations. First Nations people, particularly those who lived in First Nations communities (77.6\%, 95\% CI 75.5\%-79.8\%), were less likely to have a regular family physician than were other people in Ontario (97.7\%, 95\% CI 97.5\%-97.9\%). Continuity of care was also lower for First Nations people.

First Nations people were markedly less likely to receive specialist care from an endocrinologist $3.9 \%, 95 \%$ CI $3.6 \%-$ $4.2 \%$ v. $9.5 \%, 95 \%$ CI 9.5\%-9.6\%), and those living in First Nations communities were also less likely to receive care from a general internist $(9.5 \%, 95 \%$ CI $9.0 \%-10.0 \%$ v. $11.0 \%$, $95 \%$ CI $10.9 \%-11.0 \%)$.

First Nations people were twice as likely as other people to be admitted to hospital for ambulatory-care-sensitive conditions (2.4\%, $95 \%$ CI $2.2 \%-2.7 \%$ v. $1.2 \%, 95 \%$ CI $1.2 \%-1.2 \%)$, and 


\begin{tabular}{|c|c|c|c|c|}
\hline \multirow[b]{3}{*}{ Characteristic } & \multicolumn{4}{|c|}{ No. $(\%)$ of people } \\
\hline & \multicolumn{3}{|c|}{ First Nations people } & \multirow[b]{2}{*}{$\begin{array}{c}\text { Other people in } \\
\text { Ontario } \\
n=1357577\end{array}$} \\
\hline & $\begin{array}{c}\text { Overall } \\
n=22952\end{array}$ & $\begin{array}{l}\text { Living in First } \\
\text { Nations } \\
\text { communities } \\
n=8869\end{array}$ & $\begin{array}{l}\text { Living outside of } \\
\text { First Nations } \\
\text { communities } \\
n=14083\end{array}$ & \\
\hline \multicolumn{5}{|l|}{ Sex } \\
\hline Male & $10644(46.4)$ & $4234(47.7)$ & $6410(45.5)$ & $705528(52.0)$ \\
\hline Female & 12308 (53.6) & 4635 (52.3) & $7673(54.5)$ & $652049(48.0)$ \\
\hline \multicolumn{5}{|l|}{ Age, yr } \\
\hline$\leq 19$ & $290(1.3)$ & $111(1.3)$ & $179(1.3)$ & $11409(0.8)$ \\
\hline $20-34$ & $1605(7.0)$ & $613(6.9)$ & $992(7.0)$ & 42235 (3.1) \\
\hline $35-49$ & $5621(24.5)$ & $2202(24.8)$ & 3419 (24.3) & 188779 (13.9) \\
\hline $50-64$ & $9218(40.2)$ & $3532(39.8)$ & $5686(40.4)$ & 469665 (34.6) \\
\hline $65-74$ & 4106 (17.9) & $1597(18.0)$ & $2509(17.8)$ & $335360(24.7)$ \\
\hline$\geq 75$ & $2112(9.2)$ & $814(9.2)$ & $1298(9.2)$ & $310129(22.8)$ \\
\hline \multicolumn{5}{|l|}{ Rurality* } \\
\hline Urban & $6644(28.9)$ & $392(4.4)$ & $6252(44.4)$ & $986217(72.6)$ \\
\hline Semiurban & $4600(20.0)$ & $1119(12.6)$ & $3481(24.7)$ & 261741 (19.3) \\
\hline Rural & $5393(23.5)$ & $2400(27.1)$ & $2993(21.3)$ & 105371 (7.8) \\
\hline Remote/missing & 6315 (27.5) & 4958 (55.9) & $1357(9.6)$ & $4248(0.3)$ \\
\hline \multicolumn{5}{|l|}{ Comorbidity† } \\
\hline Low & $4984(21.7)$ & $2464(27.8)$ & 2520 (17.9) & $247756(18.2)$ \\
\hline Medium & $8868(38.6)$ & 3481 (39.2) & $5387(38.3)$ & 577934 (42.6) \\
\hline High & 9100 (39.6) & 2924 (33.0) & $6176(43.9)$ & $531887(39.2)$ \\
\hline
\end{tabular}

they were also more likely to have emergency department visits for hypo- or hyperglycemia $(1.5 \%$, 95\% CI $1.3 \%-1.7 \% \mathrm{v}$. $0.8 \%, 95 \%$ CI $0.8 \%-0.9 \%)$.

Many of the differences between populations persisted when outcomes were stratified by location (Appendix 1, Supplemental Table S2). For example, among other people in Ontario, even those who lived in remote areas were still more likely to have a regular family physician than First Nations people living in any location. However, use of endocrinologists differed by location of residence: remote-dwelling First Nations people had similar use of endocrinologists as remotedwelling other people, but First Nations people had lower use in all other locations.

\section{Interpretation}

First Nations people with diabetes in Ontario had poorer access to primary and specialist care than other people with diabetes in the province. These disparities were particularly striking for those who were living in First Nations communities. First Nations people also had more potentially prevent- able hospital admissions and emergency department visits, which can be markers of poor primary care access.

First Nations people with diabetes in Ontario were less likely to have a family physician than were other people with diabetes in the province. As primary care plays an important role in overall health, the fact that nearly one-quarter of First Nations people with diabetes living in First Nations communities did not have a family physician is concerning. It is important to highlight that family physician care delivered at community health centres and Aboriginal Health Access Centres (where physicians do not submit fee-for-service claims) was not captured within the data sources used in this study. However, less than 4\% of Ontario's First Nations people with diabetes received physician care at a Community Health Centre in 2014, and the majority of them continued to receive core primary care services from outside family physicians whose data were captured (Jennifer Rayner, Alliance Ontario: personal communication, 2020). First Nations people living in First Nations communities may also receive care through federally funded nursing stations and health centres, which may offer some of the primary care services that would otherwise 
Table 2: Age- and sex-adjusted use of health care use services of the 2 groups, 2014/15

\begin{tabular}{|c|c|c|c|c|}
\hline \multirow[b]{3}{*}{ Outcome } & \multicolumn{4}{|c|}{$\%$ of people $(95 \% \mathrm{Cl})^{*}$} \\
\hline & \multicolumn{3}{|c|}{ First Nations people } & \multirow[b]{2}{*}{$\begin{array}{l}\text { Other people } \\
\text { in Ontario }\end{array}$} \\
\hline & Overall & $\begin{array}{l}\text { Living in First } \\
\text { Nations } \\
\text { communities }\end{array}$ & $\begin{array}{c}\text { Living outside First } \\
\text { Nations } \\
\text { communities }\end{array}$ & \\
\hline Had regular family physician & $85.3(83.9-86.7)$ & $77.6(75.5-79.8)$ & $90.1(88.3-92.0)$ & 97.7 (97.5-97.9) \\
\hline $\begin{array}{l}\text { Score for continuity of care with regular family } \\
\text { physician, mean }(95 \% \mathrm{Cl})\end{array}$ & $74.6(74.1-74.5)$ & $78.1(77.3-78.9)$ & $72.8(72.2-73.4)$ & $77.7(77.6-77.7)$ \\
\hline Receiving care from endocrinologist & $3.9(3.6-4.2)$ & $2.2(1.9-2.6)$ & $5.0(4.6-5.5)$ & $9.5(9.5-9.6)$ \\
\hline Receiving care from general internist & $9.5(9.0-10.0)$ & $7.6(6.9-8.3)$ & $10.7(10.1-11.4)$ & $11.0(10.9-11.0)$ \\
\hline $\begin{array}{l}\text { Admitted to hospital for ambulatory-care- } \\
\text { sensitive condition }\end{array}$ & $2.4(2.2-2.7)$ & $2.5(2.1-2.9)$ & $2.4(2.1-2.7)$ & $1.2(1.2-1.2)$ \\
\hline $\begin{array}{l}\text { Emergency department visit for hypo- or } \\
\text { hyperglycemia }\end{array}$ & $1.5(1.3-1.7)$ & $1.1(0.9-1.3)$ & $1.8(1.5-2.0)$ & $0.8(0.8-0.9)$ \\
\hline
\end{tabular}

be available from a family physician. Even among people who have a regular family physician, continuity of care was somewhat lower for First Nations people living outside of First Nations communities. Having a regular family physician and having continuity of care are both associated with better diabetes care, ${ }^{19-21}$ which suggests that First Nations people may be at risk for poor quality of care.

First Nations people were also less likely to receive specialist diabetes care, especially if they lived in First Nations communities. Specialist physicians, particularly endocrinologists, are concentrated in larger urban centres, which may explain why use of specialist physicians decreased as rurality increased. However, except in the most remote locations of residence, First Nations people had substantially lower use of endocrinologists than comparable other people in Ontario, which suggests that there may also be systemic barriers to accessing specialist care for First Nations people. This gap in access to specialty care has been previously reported for diabetes $^{22}$ and other chronic conditions. ${ }^{23-25}$

Hospital admissions for ambulatory-care-sensitive conditions are a measure of overall health care performance, since timely, high-quality and accessible primary care can prevent many of these admissions. ${ }^{17,18}$ First Nations people had higher rates of hospital admission for these conditions than other people in Ontario, regardless of location of residence. The increased burden of admission for ambulatory-caresensitive conditions has been previously documented in First Nations people in Ontario and other Canadian provinces ${ }^{22,26,27}$ and in Métis people. ${ }^{28}$ Lavoie and colleagues ${ }^{27}$ found that First Nations communities in Manitoba with better access to community-level primary health care had lower rates of hospital admission for ambulatory-caresensitive conditions, whereas communities with limited incommunity access to primary health care services had higher admission rates.
First Nations people also had higher rates of emergency department visits for hypo- or hyperglycemia. Although the vast majority of hypo- and hyperglycemic events can be managed by patients themselves on their own, these findings suggest that First Nations people are at particularly increased risk for severe metabolic abnormalities that they were unable to self-manage. Furthermore, a disproportionate number of First Nations people live in communities that are far from hospitals, so they would attend nursing stations or other health care facilities as the only available source of acute care. Thus, these data may actually underestimate the true burden of acute metabolic complications among First Nations people in Ontario.

Our findings corroborate previous research in Ontario. ${ }^{29} \mathrm{~A}$ recent qualitative study of health care experiences of Indigenous people with type 2 diabetes showed that visits to care providers outside of their First Nation communities were considered a major challenge, not only because of geographic isolation, but also because the shortage of physicians in First Nations communities substantially jeopardized continuity of care. ${ }^{9}$

Some of the differences between First Nations people and other people in Ontario may result from geographic issues. For example, many First Nations communities are in isolated and remote locations, where access to health care services, particularly specialized services, is problematic. However, it is important to highlight the continuing impact of colonization as a key barrier to health care access. ${ }^{9,30,31}$ Given power imbalances in the patient-provider relationship, service providers ought to be sensitive to these circumstances, ${ }^{32}$ as miscommunication is a major barrier to care. ${ }^{33,34}$ Inequities in access to health care can be lessened by implementing models of care that embrace Indigenous knowledge systems and that acknowledge the social and historical context of the health of

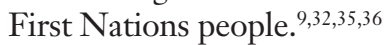




\section{Limitations}

This study has important strengths, including that it was a participatory research collaboration between academic researchers and First Nations community members, who were involved through the inception and design of the study and interpretation of the data. However, there are also limitations in the data to note. First, we were unable to capture family physician services delivered at community health centres and Aboriginal Health Access Centres, or through federally funded facilities; hence, we may have overestimated gaps in family physician care between First Nations people and other people in Ontario. However, very few First Nations people received primary care services exclusively within community health centres, so the impact of these missing data is likely negligible. In addition, hospital admissions for ambulatorycare-sensitive conditions and emergency department visits for hypo- or hyperglycemia both reflect inadequate primary care regardless of where it is delivered, and the results for these outcomes mirrored the results for family physician use. Also, any specialist care delivered outside of Ontario was not captured. This may particularly affect First Nations people living in northwestern Ontario, who may travel to Winnipeg for specialist care.

We included all people with nongestational diabetes in this study, and most people in the population with diabetes have type 2 . Use of health care services by people with type 1 diabetes may be different from that of the diabetic population as a whole, but type 1 diabetes is particularly rare among First Nations people. ${ }^{37}$

As the study relied on secondary data not collected prospectively for research purposes, diagnoses may have been miscoded, which would have led to misclassification of outcomes. In addition, we could not examine the impact of socioeconomic status on health care use, because neighbourhoodlevel household income proxies are inaccurate among First Nations people. ${ }^{13}$ Finally, First Nations people who are not registered with the Indian Register, including members of First Nations not recognized by the federal government, were not included in the First Nations population of this study.

\section{Conclusion}

Compared to other people with diabetes in the province, First Nations people with diabetes in Ontario were less likely to have a regular family physician, had lower continuity of care and were less likely to see a diabetes specialist. They also had higher rates of hospital admission for ambulatory-caresensitive conditions and higher rates of emergency department visits for hypo- or hyperglycemia, both of which are indicators of poor access to or quality of primary care. It is essential to improve health care access for First Nations people in order to reduce their burden of diabetes complications.

\section{References}

1. Starfield B, Shi L, Macinko J. Contribution of primary care to health systems and health. Milbank $Q 2005 ; 83: 457-502$.

2. Friedberg MW, Hussey PS, Schneider EC. Primary care: a critical review of the evidence on quality and costs of health care. Health Aff (Millwood) 2010;29: 766-72.
3. Hansen J, Groenewegen PP, Boerma WGW, et al. Living in a country with a strong primary care system is beneficial to people with chronic conditions. Health Aff (Millwood) 2015;34:1531-7.

4. Walker JD, Slater M, Jones CR, et al. Diabetes prevalence, incidence and mortality in First Nations and other people in Ontario, 1995-2014: a populationbased study using linked administrative data. CMA7 2020;192:E128-35.

5. Green ME, Jones C, Walker JD, et al. First Nations and diabetes in Ontario. Toronto: ICES; 2019.

6. Richmond CAM, Ross NA. The determinants of First Nation and Inuit health: a critical population health approach. Health Place 2009;15:403-11.

7. Reading CL, Wien F. Health inequalities and social determinants of Aboriginal People's health. Prince George (BC): National Collaborating Centre for Aboriginal health; 2013.

8. Greenwood M, de Leeuw S, Lindsay N. Challenges in health equity for Indigenous peoples in Canada. Lancet 2018;391:1645-8.

9. Jacklin KM, Henderson RI, Green ME, et al. Health care experiences of Indigenous people living with type 2 diabetes in Canada. CMA7 2017;189:E106.

10. Allan B, Smylie J. First Peoples, second class treatment: the role of racism in the health and well-being of Indigenous peoples in Canada. Toronto: Wellesley Institute; 2015.

11. Walls ML, Gonzalez J, Gladney T, et al. Unconscious biases: racial microaggressions in American Indian health care. 7 Am Board Fam Med 2015;28: 231-9.

12. Browne AJ. Clinical encounters between nurses and First Nations women in a Western Canadian hospital. Soc Sci Med 2007;64:2165-76.

13. Slater M, Green ME, Shah BR, et al. First Nations people with diabetes in Ontario: methods for a longitudinal population-based cohort study. CMAF Open 2019;7:E680-8.

14. Kralj B. Measuring "rurality" for purposes of health-care planning: an empirical measure for Ontario. Ont Med Rev 2000;67:33-52.

15. Weiner JP. The Johns Hopkins ACG Case-Mix System version 6.0 release notes. Baltimore: Johns Hopkins University; 2003.

16. Stukel TA, Glazier RH, Schultz SE, et al. Multispecialty physician networks in Ontario. Open Med 2013; 7:e40-55.

17. Caper P. The microanatomy of health care. Health Aff (Millwood) 1993;12: 174-7.

18. Rosano A, Loha CA, Falvo R, et al. The relationship between avoidable hospitalization and accessibility to primary care: a systematic review. Eur 7 Public Health 2013;23:356-60.

19. Kiran T, Victor JC, Kopp A, et al. The relationship between primary care models and processes of diabetes care in Ontario. Can 7 Diabetes 2014;38: $172-8$.

20. Kiran T, Kopp A, Glazier RH. Those left behind from voluntary medical home reforms in Ontario, Canada. Ann Fam Med 2016;14:517-25.

21. van Walraven C, Oake N, Jennings A, et al. The association between continuity of care and outcomes: a systematic and critical review. 7 Eval Clin Pract 2010;16:947-56.

22. Campbell DJT, Ronksley PE, Hemmelgarn BR, et al. Association of enrolment in primary care networks with diabetes care and outcomes among First Nations and low-income Albertans. Open Med 2012;6:e155-65.

23. Martens PJ, Sanderson D, Jebamani L. Health services use of Manitoba First Nations people: Is it related to underlying need? Can 7 Public Health 2005;96: S39-44.

24. Gao S, Manns BJ, Culleton BF, et al. Access to health care among status Aboriginal people with chronic kidney disease. CMAJ 2008;179:1007-12.

25. Jetté N, Quan H, Faris P, et al. Health resource use in epilepsy: significant disparities by age, gender, and aboriginal status. Epilepsia 2008;49:586-93.

26. Shah BR, Gunraj N, Hux JE. Markers of access to and quality of primary care for Aboriginal people in Ontario, Canada. Am F Public Health 2003;93:798-802.

27. Lavoie JG, Forget EL, Prakash T, et al. Have investments in on-reserve health services and initiatives promoting community control improved First Nations' health in Manitoba? Soc Sci Med 2010;71:717-24.

28. Carrière GM, Kumar MB, Sanmartin C. Hospitalization for ambulatory care sensitive conditions among urban Métis adults. Health Rep 2017;28:3-11.

29. Booth GL, Hux JE, Fang J, et al. Time trends and geographic disparities in acute complications of diabetes in Ontario, Canada. Diabetes Care 2005;28:1045-50.

30. Anderson I, Crengle S, Leialoha Kamaka M, et al. Indigenous health in Australia, New Zealand, and the Pacific. Lancet 2006;367:1775-85.

31. Vallesi S, Wood L, Dimer L, et al. "In their own voice" - incorporating underlying social determinants into Aboriginal health promotion programs. Int 7 Environ Res Public Health 2018;15:E1514.

32. Peiris D, Brown A, Cass A. Addressing inequities in access to quality health care for Indigenous people. CMA7 2008;179:985-6.

33. Cass A, Lowell A, Christie M, et al. Sharing the true stories: improving communication between Aboriginal patients and healthcare works. Med 7 Aust 2002;176:466-70.

34. Mbuzi V, Fulbrook P, Jessup M. Indigenous peoples' experiences and perceptions of hospitalisation for acute care: a metasynthesis of qualitative studies. Int 7 Nurs Stud 2017;71:39-49.

35. Cameron BL, Carmargo Plazas MdelP, Salas AS, et al. Understanding inequalities in access to health care services for Aboriginal people: a call for nursing action. ANS Adv Nurs Sci 2014;37:E1-16. 
36. Horrill T, McMillan DE, Schultz ASH, et al. Understanding access to healthcare among Indigenous peoples: a comparative analysis of biomedical and postcolonial perspectives. Nurs Inq 2018;25; 12237.

37. Dyck R, Osgood N, Lin TH, et al. Epidemiology of diabetes mellitus among First Nations and non-First Nations adults. CMA7 2010;182:249-56.

Affiliations: ICES (Shah, Slater, Frymire, Khan, Walker, Green); Division of Endocrinology (Shah), Sunnybrook Health Sciences Centre; Department of Medicine (Shah), University of Toronto, Toronto, Ont.; Health Services and Policy Research Institute (Frymire, Khan, Green) and Department of Family Medicine (Slater, Green), Queen's University, Kingston, Ont.; Memory Keepers Medical Discovery Team (Jacklin), Department of Family Medicine and Biobehavioral Health, University of Minnesota Medical School, Duluth, Minn.; Chiefs of Ontario (Sutherland), Toronto, Ont.; School of Rural and Northern Health (Walker), Laurentian University, Sudbury, Ont.; Department of Family Medicine (Green), Kingston Health Sciences Centre, Kingston, Ont.

Contributors: Baiju Shah and Michael Green conceived the study. Shahriar Khan analyzed the data. Baiju Shah drafted the manuscript. All of the authors were involved in designing the study and interpreting the data, revised the manuscript critically for important intellectual content, approved the final version to be published and agreed to be accountable for all aspects of the work.

Funding: This study was supported by an Ontario SPOR SUPPORT Unit IMPACT Award and by ICES, which is funded by an annual grant from the Ontario Ministry of Health and Long-Term Care. Additional support was provided to Michael Green through the Brian Hennen Chair in Family Medicine, Queen's University, and to Jennifer Walker through a Tier 2 Canada Research Chair in Indigenous Health.

Data sharing: The data set from this study is held securely in coded form at ICES. Although data-sharing agreements prohibit ICES from making the data set publicly available, access may be granted to those who meet prespecified criteria for confidential access. The full data set creation plan and underlying analytic code are available from the authors on request, with the understanding that the programs may rely on coding templates or macros that are unique to ICES Data from this study are not available for sharing.

Acknowledgements: The authors' partner through the early design, implementation and final dissemination of this project was the Chiefs of Ontario. Their many contributions were key to the content and quality of the project. The authors also acknowledge the members of the project Patient Advisory Committee for providing insightful and thoughtful input; their advice made a substantial contribution in shaping the work. The authors also acknowledge the First Nations people from Big Grassy River First Nation, Alderville First Nation, Caldwell First Nation, Six Nations of the Grand River and Moose Cree First Nation with diabetes who shared their personal experiences. The authors also thank Sue Schultz and Rahim Moineddin for their contributions to data set creation and cleaning, and to statistical analysis.

Disclaimer: This study was supported by ICES, which is funded by an annual grant from the Ontario Ministry of Health and Long-Term Care (MOHLTC). The opinions, results and conclusions reported in this article are those of the authors and are independent from the funding sources. No endorsement by ICES or the Ontario MOHLTC is intended or should be inferred. Parts of this material are based on data and information compiled and provided by the MOHLTC and the Canadian Institute for Health Information. The analyses, conclusions, opinions and statements expressed herein are solely those of the authors and do not reflect those of the data sources; no endorsement is intended or should be inferred.

Supplemental information: For reviewer comments and the original submission of this manuscript, please see www.cmajopen.ca/content/8/2/ E313/suppl/DC1. 